\title{
Editorial for the Special Issue on Social Networks in Construction
}

\author{
The Journal of Construction Management and Economics \\ StephenPryke ${ }^{1}$, Sulafa Badi ${ }^{1}$ and Lena Bygballe ${ }^{2}$ \\ ${ }^{1}$ The Bartlett School of Construction and Project Management, University College London \\ ${ }^{2}$ Department of Strategy, BI Norwegian Business School, Oslo, Norway
}

\section{Social Networks in Construction}

For some time, traditional conceptualisations, analyses, and design of project organisations have been criticised for being inappropriate to capture the complexity of current construction and engineering projects (Blomquist et al., 2010). These projects are increasingly complex, not only in a technical sense, but even more so in terms of the organisational systems needed to design and execute them. Previous project management models and existing ways of understanding, organising and managing projects seem to have reached their limit of application, showing diminishing results (Winter et al., 2006; Chinowsky et al., 2008). Accordingly, there have been calls for new models and analytical tools that capture the social dimensions of project organising, and the essence of the inter-firm relationships that comprise the construction project coalition (Pryke, 2012). It is argued that the relationships associated with the dynamic, transient and 'time-defined' temporary organisation require further research (Burger and Sydow, 2014).

As a response to this call, recent perspectives within construction project literature have come to focus on the social, relational and 'self-organising' dimensions of projects to capture their technical and social complexities. For example, studies on megaprojects show a need for 
relying on the ability of self-organising rather than the traditional project management techniques such as planning, scheduling, and risk analysis (Pryke, 2012, 2017; Pryke et al., 2017). It is argued that to deliver successful projects, there is a need to focus upon 'actors and their behaviours' in projects (Blomquist and Lundin, 2010:7) and find out 'what project managers do' (Geertz, 1973) rather than 'what is being done' (Blomquist and Lundin, 2010:13). In accordance with such a perspective and combined with the increased attention given to the relationships between project actors, a stream of research has emerged within the construction literature focusing on the understanding of construction and engineering projects as social networks (Zheng et al., 2016). Wasserman and Faust (1994) define a social network as a set of actors connected through clearly defined relations. These relations can be directed, that is, they flow from one actor to the other, in terms of information, trust and affection perhaps, or undirected, for example, sharing an office. Relations can also differ in terms of their strength ranging on a quantifiable continuum from weak to strong ties (Granovetter, 1973), and their effect in terms of positive or negative affective content (Labianca, 2014). The social network concept provides a framework for testing theories about structured social relationships (Wasserman and Faust, 1994). As such, it constitutes an alternative to the assumption of independent social actors, often found in traditional project management theory.

The rapid growth of social network theory and the associated social network analysis (SNA) in construction research has mainly been driven by the fledgling conceptualisation of a construction project as a temporary network embedded in a permanent network (Dubois and Gadde, 2000; 2002), with a limited-time cycle and specific objectives delivered by groups of actors engaging in complex problem-solving processes and interacting through formal and informal relationships (Li et al., 2011; Chowdhury et al., 2011). While some network scholars have been concerned with the network characteristics of the construction industry as such, 
analysing interdependencies between contractual parties (e.g., Bygballe et al., 2013; Dubois and Gadde, 2000; 2002; Håkansson and Ingemansson, 2013), social network scholars are more often concerned with overcoming the task versus social structure paradigm.

Inspired by Nohria and Eccles (1992), our basic premise for this special issue is that the reasons why the application of (social) network theory and the analysis of network data facilitate an understanding of construction project organisations relate to three key assumptions: 1) all human activity is the product of human relationships; 2) actors contribute to the environment within a given network and are a function of that environment - for example, prominence of an individual is related to the prominence of others and the number of other prominent actors, and finally; 3) we can never understand the firm or the project, and the nature of their relationships, without looking at the remainder of the networks and forming an understanding of those networks.

Conceptualising a construction project as a network allows for an in-depth analysis and understanding of individual and organisational behaviour in construction project organisations by facilitating a relational and contextual conceptualisation of the complex networks in which those actors are embedded (e.g. Mead, 2001; Hossain and Wu, 2009; Alsamadani et al., 2013). Furthermore, looking at project function-related communication networks, which is a key issue in SNA, enables a researcher to visualise communication networks and to quantify the roles of the actors within that network. We believe that this is important for overcoming the perceived challenges of traditional project management models.

Despite the attention given to social networks and the number of contributions provided over the past 10-15 years, compared to other management disciplines, studies adopting a network- 
analytical perspective remain scarce in the construction management domain (Zheng et al., 2016). This special issue is therefore motivated by two aims: first, to continue the dialogue between the two fields of social network theory and construction management with the aim of stimulating further theory development and providing empirical insight into creating effective project organisations and networks. Specifically, there is a gap in our understanding of the transformation that occurs once projects move from contract award to project delivery. At this point custom and practice and 'industry recipes' (Spender, 1989) and their embedded, discipline-specific routines are established and remain transient throughout the delivery phases. Second, to elevate the status of the current research frontier within social networks in the construction domain. We believe that the eight articles included in the special issue contribute to fulfil both these two aims. The articles examine a wide range of issues concerning the construction industry, including knowledge sharing, managing socio-political stakeholderrelated risks, and coordinating inter-organizational resources and collaboration, among others. These issues are explored in a variety of contexts such as intra-organisational teams, interorganisational disaster recovery and Private Finance Initiative equity markets, and with different methodological approaches. Collectively, the articles demonstrate the usefulness of social network theory and SNA as a conceptual and methodological lens in the exploration of major issues in construction project management.

In the remainder of this editorial, we outline a research agenda for social network research in construction and key topics on which we believe the eight articles included in the special issue contribute. At the end we present the respective articles. 


\section{Towards a social network research agenda in construction}

There are three key issues that we find particularly vital for the further development of the social network research agenda in construction, and which we believe have been informed by the eight articles in the special issue: 1) a better understanding of the role of individual actors and functions in construction projects and the organisations that comprise the supply chains and networks relating to those projects; 2) an exploration of the effectiveness or otherwise of relationships in delivering successful construction projects and superior organisational outcomes, finally 3) suggestions of how to move from resource acquisition through procurement, towards repeatable project delivery processes, or routines, in the construction setting. In the following, we address these issues.

\section{A better understanding of the role of individual actors in projects and organisations}

As we stated earlier in this editorial, the increasing complexity and risks, particularly in very large construction and engineering projects are not being matched by an equivalent pace of change in our understanding and analysis of those projects. Winter et al (2006) have identified that one source of complexity associated with projects is the complexity of social interaction. Indeed, the increasing complexity in projects both organisationally and technically is driving a need for increasing visibility in the social systems and networks that are required to deliver the wide range of functions that projects comprise. The relative permanence of roles assumed during contract formation is contrasted with the transience of social relationships, whether in a recreational context, or an organisational one. Winter, et al (2006) recognise the importance of understanding individual actors' prominence (which they describe as power). Prominence is often operationalised as centrality, a social network concept fundamentally concerned with the 
structural importance of an actor's position in a network (Freeman, 1987). The way in which prominence in social networks is manifested or perhaps exploited (Bresnen, 2006) is increasingly important in our understanding of the functioning and effectiveness of construction projects. Prominence in project functional networks is acquired by individual project actors within the context of each of the networks with which they are associated. Pryke (2017) argues that the role allocated by contract is essentially of less importance than the network roles acquired or imposed by the network of other actors; roles allocated at procurement stage are essentially incomplete and are subject to redundancy over the contract periods.

The concept of prominence could be employed to identify important actors not only within projects, but also within construction firms as well as within construction markets. The work of Hossain (2009) and Hossain and Wu (2009) has shown that an actor's centrality in the communications network largely affects their ability to coordinate the actions of others. In addition, the work of Poleacovschi et al.'s (this issue) in a large US construction firm has underlined the efficiency gains, particularly time saving, that individuals can obtain by their closeness to a knowledge provider that holds a prominent network position. This can be especially significant in time-constrained construction projects. Murray and De Biasio (this issue) also used prominence to identify active sellers in the UK's Private Finance Initiative (PFI) secondary equity market and assessed the relationship between a seller's prominence and their overall financial returns. Their findings have shown that return on equity is not, evidently, improved by higher level of prominence, when compared to the average returns. Zdziarski and Boutilier (this issue) also used centrality to identify influential stakeholders, those that strategic interventions should target in order to reduce socio-political risks from stakeholders that may otherwise jeopardize the continuity of the project, while Lepropre et al. (this issue) 
examined the centrality of organisations in the community networks. What is powerful about the SNA measures of centrality is that they are capable of identifying prominent actors in a network, be it individuals, teams or organizations. In the context of projects, we suggest a need to develop management interventions associated with these 'network roles' as against the 'project roles' on which we currently tend to focus.

\section{Exploration of the effectiveness or otherwise of relationships in delivering successful projects and superior organisational outcomes}

Some might argue that we have made little progress in understanding interdependencies among people and functions in projects, despite the early work of Higgin and Jessop (1965) in this area. The identification of interdependent actor relationships forming networks - how they are facilitated, established, and maintained, and subsequently decay (perhaps inevitably and desirably), might inform the language and terminology that we use to describe project functions. Project management represents an eclectic group of functions brought together to facilitate the delivery of a project. These functions, such as design management, cost management, instructions and incentives, among others, provide a classification of networks that support a given project (Pryke, 2012). The tendency towards archaic models of projects and their management has led the construction industry into a position where vitally important project functions, such as problem-solving is not procured, and hence, this fundamentally important aspect of the design and execution of projects is essentially self-organised (Pryke, et al 2017). An important question is how to design and manage the relationships supporting these project functions. 
With regard to project performance, SNA offers an interesting lens. Project performance has tended to be quantified using data relating to cost, time and quality, the so-called 'Iron Triangle' (Barnes, 1988). However, the establishment of which aspects of the design of systems and organisational structures in projects that are related to project performance remains problematic. Indeed, it might be argued that the formulation of metrics for project performance is problematic in itself. Some might also argue that projects can satisfy the metrics associated with the iron triangle and still fail to deliver value to project stakeholders. By visualising the network structures, SNA may help identifying which structures that are likely to influence project performance and offer a broader view of various performance indicators, such as the effectiveness of communication, collaboration and the management of stakeholder relationships, among others, which are fundamental for project success.

Furthermore, SNA offers an interesting lens to examine communication relationships, collaboration and coordination in construction, among which is the work of Mead (2001) visualising project teams and Alsamadani et al. (2013) and Lingard et al., (2014) studies of health and safety communication. The work of Kang and Loosemore (2013), and Di Marco et al. (2010) are also insightful as they revealed the important role played by communication brokers and cultural boundary spanners in facilitating effective communication in projects. The most recent work of Pryke et al., (2017) underlined the small-world topography that characterises the self-organisation mechanisms in construction teams' communication using cluster detection. In addition, collaboration within projects is an important dimension of project success which has been examined using SNA such as in the work of Park et al. (2011) on overseas collaborative ventures and the studies of Son and Rojas, (2011) and Liu et al., (2015) exploring the evolution of collaboration within inter-organisational networks. Lepropre et al. (this issue) add further insight by analyzing multiple coordination time periods. Their findings 
show that networks are not static, but dynamic and in the case of their case study of disaster recovery project, the network becomes more decentralised over time.

Yet another interesting issue relates to risk management, which is one of the earlier concepts explored through SNA. The work of Loosemore (1998) is among the first to take a social network perspective to the management of construction crises, while the more recent work of Wambeke et al, (2013), used the technique to elucidate the risks associated with the social networks of multiple trades working interdependently in construction projects. The work of Zdziarski and Boutilier (this issue) further identified that socio-political risks from stakeholders are among the most unpredictable types of risk faced by construction projects. Understanding relationships among project stakeholder is indeed critical for project success and Zdziarski and Boutilier, looking at the concept of 'social license' (e.g. Morrison, 2014; Syn, 2014), have shown that strategic interventions aimed at managing these risks in projects could be facilitated by greater understanding of the structure and dynamics of stakeholder networks. They argue that not all stakeholders are equally important and strategic interventions should be aimed at the stakeholders with higher influence. The work of Lepropre et al. (this issue) also showed that relationships do not remain static but evolve dynamically over time, and in the case study they explored, these relationships were weak in early recovery phases but strengthened in later stages.

Knowledge and its effective management in project settings are also important ingredients for project success, and a number of authors have explored knowledge management issues through the lens of SNA. An example is the work of Javernick-Will (2011) looking at knowledgesharing ties across geographical boundaries in global intra-firm networks and the work of Zhang et al., (2012) that focused on the sharing of tacit knowledge for integrated project 
delivery. Poleacovschi et al. (this issue) further argue, that time savings in knowledge sharing networks are enabled by strong connections, and based on frequent knowledge sharing, which saved the knowledge seeker the most time on her daily tasks. In the time-constrained construction industry, managers can improve knowledge sharing by promoting frequent communication and interaction. However, the work of Keung and Shan (this issue) have shown that, despite industry calls for greater knowledge sharing, contractor firms remain reluctant to share their key knowledge within their interfirm project networks due to fear of losing their competitive edge in the mostly competitively-tendered construction project markets.

In 2012, Whyte and Levitt recognised that information and communication technologies shape the structures that we use in projects. Despite this, we see very little reflection of this issue in procurement and project management strategies in industry. The work of Badi and Diamantidou (2017) have shown how the adoption of Building Information Modelling (BIM) may change the structure of the project network and actors roles and relationships. Papadonikolaki et al. (this issue) further elaborates on these changing structures by examining the role of formal (i.e. contracts, agreements) and informal relations (i.e. social interactions) that emerge in BIM-enabled supply chain partnerships in the Netherlands and how they influence the relationships between the partners. Their findings suggest that having symmetrical and jointly fostered formal and informal relations contributes to integration and longevity of BIM-enabled partnerships. Ultimately, perhaps we shall come to identify optimum project relationships networks in projects.

In sum, taking a broader view and zooming out from construction projects to construction markets, we argue that the relationships between firms in construction markets is critical for a 
firm’s performance and business development. Focusing on interfirm networks (Nohria and Eccles, 1992; Grandori and Soda, 1995), social network theory can be a powerful theoretical and analytical tool that can help firms to understand the significance of their network characteristics in determining their organisational outcomes. The work of Keung and Shen (this issue) have shown that building effective interfirm network relationships, particularly the networking techniques of supporting information exchange among project actors, organising project communication, and creating learning capacity are significant strategies that can improve a contractor's business competitiveness particularly in terms of increasing market share through securing more construction contracts and delivering projects successfully. Hence, firms that are able to develop an understanding of their network position can then develop strategies to improve their performance and competitiveness in their markets (e.g. Baum et al., 2014). However, there remain a paucity of studies examining the effect of establishing effective inter-firm networks on the competitiveness of firms in construction.

\section{Moving from resource acquisition through procurement, towards repeatable project delivery routines}

Networks are a response to the uncertainty found in most project environments (Powell, 1990). Part of that uncertainty is associated with the replication of systems between projects. In the context of complexity in systems and technology, individuals trying to survive through the delivery of a particular role are driven by the need to acquire and disseminate information. Networks are certainly a response to the need for project actors, most fundamentally, to gather information from other actors, process that information and disseminate the processed information to other project actors (Pryke, 2015). The transformation from resource acquisition to project delivery requires a transition and these frequently repeated transitions create routines 
(Billinger and Becker, 2014) of which relatively little is known at present. The codification of those routines could be facilitated by the application of network principles; the analysis and presentation of the nature of those relationships is then possible through the application of network theory and SNA. The point here is that as a project moves into the typically lump-sum based contract award and delivery phases, a transition occurs. The resources procured make a start on establishing systems to achieve the functions required for project delivery. Contract conditions and post contract governance are essentially incomplete in terms of clearly defining the systems necessary for each project function. Many of the traditional assumptions that we make about the contracting systems (Winch, 1996) are becoming redundant and inappropriate to explain and understand these relationships. For example, the formulation of a lump sum contract based upon finalised information relating to design has always created incompleteness in contracts associated with projects (Walker and Pryke, 2008). This is exacerbated by increasing complexity and requires a shift in focus away from the routines associated with managing dyadic contractual relationships towards an emphasis on allocating appropriate network functions and monitoring the effectiveness of these functions over the design and delivery period.

This implies that the pressure is on project actors to establish shared meaning. Shared meaning in relation to the definition of the project; shared meaning in relation to an individual's own role and the role of others; and shared meaning in relation to the detailed information that is being disseminated by others. Sense-making is context-specific and each project must create a system of meaning. Transforming these systems of meaning has always been a challenge for project based industries and Fellows and Liu's (this issue) discussion is relevant here. The lack of routines that are effective in delivering excellence in projects places a burden on those that manage projects and it is argued here that the lack of adequate and robust routines tends to 
lead to the formation of ‘self-organising' networks (Pryke, et al, 2017). The temporary systems that project actors, individually and collectively, establish in our projects might be more readily replicated if we could find a way to graphically represent those temporary systems; this representation of the social network data gathered could be used to train and manage relevant project staff (Pryke, 2017). The interruption of relationships between supply chain members caused by the vagaries of the contracting systems (Winch, 1996) coupled with the partial uniqueness of individual construction projects (Ludin and Soderholm, 1996) are critical project success factors (Manning and Sydow, 2011). The contracting system forces project actors to transition from a position where they have relatively little information about objectives and process, into an environment of high uncertainty and complexity. The articles in this special issue deal, in a wide variety of ways, with the formation of functional relationships in projects dealing with these transitions.

\section{Summary of the articles in this special issue}

Below we summarise each of the articles and their key findings. We will also highlight how they relate to each other and how they contribute to the overall study of networks in construction projects.

The first three articles show how SNA can be used to study efficiency, effectiveness and competitiveness in the construction sector. In the first article, Poleacovschi, Javernick-Will and Tong consider the relationship between time savings and knowledge sharing connections, and thereby focus on the efficiency issue in construction projects. These authors apply SNA to study which knowledge sharing connections provide time savings. Since construction is a highly intensive, knowledge sharing and time sensitive environment, where people need to be able to access others in a timely matter to solve problems quickly, the authors argue that 
knowing which connections that facilitate time savings is essential for companies in this sector. Their analysis of 10,849 knowledge sharing dyads in one department in a large, US multinational construction and engineering company, shows that time savings are enabled by strong connections and closeness to a knowledge provider that holds a central network position. The key contribution of Poleacovschi et al.'s research is to highlight the importance of the network context for understanding the benefits of strong versus weak connections. They conclude that strong connections may be particularly important in labour intensive construction projects where time pressures are high.

In the second article, Murray and De Biasio use SNA on transactions in the UK's Private Finance Initiative (PFI) secondary equity market to examine the notion that prominence of sellers can improve overall financial returns. This market is emerging, and has increased in size and maturity over the years as primary investors, principally contractors, liquidate their stakes. Analysing transactions in the European Services Strategy Unit PPP equity database, the authors identified the actors in this market in terms of active sellers and buyers, and thereby the levels of competition, as well as their characteristics in terms of prominence (out-degree centrality), based on their ego network's relations. The SNA also revealed ties created through the exchange of equity between actors. Based on the analysis, the authors conclude that isolating returns on equity based on capital appreciation for a sample of transactions reveals that annualised return on equity is seemingly not improved by higher level of out-degree centrality, when compared to the average returns. The paper contributes in showing how SNA enables financial assessment of investors (nodes) in the context of their market (network), which in turn, may be helpful in the further development of the PFI initiatives. 
The work of Keung and Shen illustrates the effectiveness of project interfirm network relationships as a strategy to strengthen a firm's competitiveness in construction market. The authors argue that the five networking techniques of supporting information exchange among project actors, organising project communication, sharing knowledge, promoting networking culture and creating learning capacity are significant strategies that can improve a contractor's business competitiveness. Based on a study of 119 Hong Kong based contractor firms, their findings have shown that business competitiveness, particularly in terms of winning contracts and carrying out projects successfully, can be largely enhanced by facilitating information exchange, establishing project communication and building learning capacity, with knowledge sharing and networking culture found to have a less prominent effect. Networking was particularly found to offer contractors a competitive edge by increasing market share through securing more construction contracts,

The following two articles address the risks and complexity involved in construction settings. Zdziarski and Boutilier starting point is the observation that socio-political risks from stakeholders represent a key, but often unpredictable risk in any construction project. When conflicts with stakeholders delay or halt project progress, the project has lost its social license. It is therefore paramount for project managers to understand which stakeholders that can potentially halt the project and which strategies they can use to gain and maintain social license. They integrate insight from stakeholder theory and SNA, and use a housing project example, to develop an approach that can help project managers in identifying which stakeholders to focus on and revealing their common ground. The research highlights that strategic interventions aimed at gaining and maintaining a 'social license to build' must focus on the stakeholders that matter (i.e. those with higher influence), since not all stakeholders are equally 
important. Such interventions, it is argued, should in particular focus on facilitating conversations and collaboration between stakeholders with common interests.

The article by Lepropre, Opdyke, Javernick-Will and Koschmann concerns the importance of inter-organisational resource coordination in disaster response and recovery. They argue that response and recovery efforts involve a complex web of stakeholders that rapidly assemble to plan and reconstruct infrastructure, and additional complexity is added in developing countries where international organisations must work alongside local partners in the face of challenging resource constraints. Despite the posited importance of inter-organisational coordination, the authors notice that poor resource allocation continues to plague response and recovery efforts. Based on a study of the reconstruction in the Philippines following Typhoon Haiyan in 2013, they unpack the community inter-organisational structures that arose during post-disaster recovery. Drawing upon social network analysis, they compared coordination between 86 organisations working in 20 communities in terms of (1) type of resources coordinated by the organisations, (2) centrality of organisations in the community networks, and (3) changes in the coordination networks over time. The findings suggest that humanitarian organisations can improve resource coordination by integrating local municipalities and government agencies earlier into coordination processes under the UN cluster system. Further, the authors recommend that donors should seek to allocate additional funding to support transition of expatriate to local staff, as this handover was found be a significant barrier to sustained coordination.

The next two articles deal with innovations in the construction sector - Supply Chain Management (SCM), which can be considered a (relatively) new management philosophy in construction, Building Information Modelling (BIM), which is a new technology and Industrial 
Building (IB). Papadonikolaki, Verbraeck and Wamelink focus on the combination between SCM and BIM, which both are aimed at integration between construction partners. While SCM is a practice and management philosophy oriented toward integrating material flows and information, BIM is a technology for integrating information flows among multi-disciplinary teams. However, despite recent interest in combining the two, Papadonikolaki et al. argue that we still know little about the impact of combining these concepts, particularly how the formal and informal relations that emerge influence the relationships between the partners. Based on interview data and Social Network Analysis of two BIM-enabled Supply Chain (SC) partnerships in the Netherlands, they conclude that having symmetrical and jointly fostered formal and informal relations contributes to integration and longevity of BIM-enabled SC partnerships. The key contribution of this research is to highlight the relational aspect of BIM implementation, which is revealed by a combination of SNA and in-depth interview data, illustrating the benefits of mix methods.

London and Pablo's starting point is the observation that fragmentation continues to characterise the Australian construction industry, and the uptake of Industrial Building (IB) is low, despite the perceived benefits. The authors attribute this to the need for extraordinarily large-scale collaboration in IB. Thus, according to London and Pablo, we need to expand our understanding of collaboration in this setting. The authors argue that further conceptualization of collaboration suitable to IB settings should draw on concepts from Actor Network Theory, particularly that of prime mover, translation, convergence, relational materiality, stability and multiplicity. Together with findings from two case studies of collaborative housing construction networks using IB technologies in Australia, the authors use these ANT concepts to develop a conceptualisation of collaboration in IB settings. This conceptualisation involves humans and non-humans (e.g. objects), seeks coherence but not conformity and emphasises 
the management of tensions between integration and separation, stabilisation and destabilisation. They argue that this conceptualization is helpful for achieving the overall ideal of integration in what they consider a fundamentally fragmented industry. The key contribution of this research is to enrich existing theoretical conceptualisations of collaboration, providing an alternative conceptualisation based on ANT that sensitives researchers (and practitioners) to nuances of collaborations that traditional theories and approaches tend to overlook.

Fellows and Liu add a social constructionist perspective to the wide range of approaches represented in this special issue. They deal with the idea of the 'becoming ontology' - practice emerging under specific conditions of power, structures and intentions. The process philosophy provides perhaps a more dynamic approach to the study of construction and one that relates more specifically to uncertainty in the project environment, than is offered by more traditional analysis of projects. There is a link here between this social constructionist position and the point made earlier in this editorial that traditional methods of analysis and indeed managing projects have become overwhelmed by increasing complexity, both technically and structurally. Fellows and Liu deal with the issue of fragmentation and this is most apposite given the context of networks and the rapidly increasing levels of connectivity between individuals, whether for business or recreation. They make the case for the study of networks to explore the systems associated with 'strategic action fields'. In this way they propose that we can understand more clearly, 'the interpretation of myriad signals' received by project actors and shared meaning which is content specific and determines the communities that establish. Fellows and Liu underline the importance of the move towards using networks to understand the nature of construction, how and where boundaries are established and how systems within construction operate. The dynamism of the project, post contract, and the need to understand this dynamism is a theme running through this special, issue. 


\section{Concluding remarks and future research}

The eight contributions and 20 contributors in this special issue demonstrate the usefulness of social network analysis in offering an analytical and methodological lens on several issues concerning the construction industry. The eight contributions provided insights in relation to: time-saving through knowledge sharing networks, improving financial returns through network position in PFI equity markets, increasing business competitiveness through inter-firm network relationships, managing socio-political stakeholder-related risks in projects, coordinating interorganisational resources in disaster response and recovery, combining Supply Chain Management (SCM) and Building Information Modelling (BIM), and sense-making in the strategic action field (SAF) of construction. Our contributors have sought to link social networks to specific trends and innovations in the sector- Murray and De Biasio, Papadonikolaki et al. and London and Pablo - examining PFI, SCM, BIM and IB. Complexity in construction projects renders traditional methods of analysis and managing projects redundant.

These issues are explored in a variety of contexts such as a large US construction firm, the UK Private Finance Initiative (PFI) secondary equity market, disaster stricken areas following Typhoon Haiyan in the Philippines, Hong Kong’s construction markets, BIM-enabled Supply Chain (SC) partnerships in the Netherlands and Industrial Building (IB) projects in the Australian construction industry. Lepropre et al., in particular, deal with an important, but as yet relatively under researched empirical setting in construction, namely disaster recovery. The study of Murray and De Biasio is also interesting because it deals with an innovative project delivery/financing form (PFI) and adopts a market-wide network boundary facilitated by the availability of unique database. The articles also cover a range of SNA concepts, such as strong 
vs weak ties, centrality and prominence, the structure of networks and how it changes in network over time. Zdziarski and Boutilier work combines SNA and stakeholder theory. Actor Network Theory (ANT) was adopted by London and Pablo to develop an alternative conceptualization of collaboration in Industrial Building (IB) based on ANT and highlight with that the importance of non-humans - which in turn would be interesting to connect to BIM in future research. In line with London and Pablo, Fellows and Liu provide an overall integrative framework focusing on a combination of strategic action fields (SAF) and sense making perspectives.

We have argued that a better appreciation of the 'network' roles of individual actors is needed to advance our understanding of the functioning of projects, construction firms and construction markets. The authors of this special issue have advanced our understanding of the concept of prominence which identifies the structural importance of an actor's position in the network. We have seen that efficiency gains can be accrued by individuals through time-saving ties to prominent knowledge providers (Poleacovschi et al.) and that strategic interventions aimed to reduce socio-political risks in projects should target prominent stakeholders (Zdziarski and Boutilier). Further research could further our understanding of the management interventions associated with these 'network roles. Our authors have also shown that prominence, however, may not result in superior financial return in the UK's Private Finance Initiative (PFI) secondary equity market (Murray and De Biasio). Nevertheless, as argued by Murray and De Biasio the hypothised relationship between network prominence and competitive advantage remain valid until proven or disproven by wider empirical evidence. We invite the scholarly community to assume this challenge. 
In addition, the articles presented here have each, individually, to a greater or lesser extent, contributed to our understanding of the effectiveness of relationships in delivering successful projects and superior organisational outcomes. For example, individuals to reduce time working on tasks by being frequently connected to well-connected actors (Poleacovschi et al.) and the fostering of formal and informal connections was found to support the integration and longevity of BIM-enabled partnerships (Papadonikolaki et al.). The examination of BIMenabled project through the lens of SNA remains in its infancy and forms an interesting arena for future research effort. In addition, networking, i.e. the building of inter-firm relationships in projects, was also found to strengthen a contractor's business competitiveness (Keung and Shen). Further research linking network characteristics to different competitiveness attributes would be valuable. Networks are also found to be dynamic and evolve through multiple coordination time periods (Lepropre et al.). As Lepropre et al point out, further research is needed to examine the role of these dynamic networks in building long-term community resilience. Indeed, how network resilience can be cultivated and supported is an area that warrant further research effort.

We have also shed the light on the concept of routines and how the transformation in projects from resource acquisition through procurement to project delivery requires a transition and these frequently repeated transitions create routines. The application of network theory and SNA could support the codification of those routines; an area where future research is certainly needed. Fellows and Liu have paved the way by making a case for the use of networks to understand the systems that project actors construct through organising and sense making and how they are driven by 'strategic action fields'. The combination of sense making and strategic action fields can offer an interesting avenue for future research in construction networks. 
Scholars within project management have for some time now addressed the inferiority of traditional approaches to project management, arguing that they have not given sufficient weight to the dynamics of human relationships and the fact that the project definition and the actors' role within that project are socially constructed (Cicmil et al., 2006; Blomquist et al., 2010). We concur with this view, believing that the application of network theory to construction is as inevitable as the application of network theory to our purchases through Amazon. Focusing on networks rather than individual actors, dyads and/or chains, we argue, provides a powerful analytical tool. Retrospectively and increasingly longitudinally, analysis in construction will provide the theory and tools to understand and manage the industry and its projects in the future. This is an exciting time for construction.

Projects are delivered through social networks - networks of actors responding to the pressures of finding and dissemination information in a highly uncertain environment. It is perhaps surprising that we know relatively little about the topography of these networks. Also how the formation of these networks might be embedded and managed over time. Communication networks evolved and naturally decay over time. The behaviour of project actors and the contact of the networks are both influential in the speed and appropriateness of the evolution and decay of these networks. The analysis of this human behaviour, the codification of this behaviour and the dissemination of the analysis is well served by the terminology and analytical routines associated with social network analysis. In time, the construction industry will use the findings of academics in the field of social network analysis applied to construction to inform the recruitment of network actors and to define their roles in relation to networks rather than ill-defined, and of necessity transitory, project outcomes. At this point we move forward to facilitate project networks relating to project functions. We move away from an emphasis on 
monitoring, in particular, cost and time through the analysis of relatively simply models representing those two aspects of project definition.

Finally, the authors and guest editors highly appreciate the rigorous and timely reviews provided by the diligent reviewers whose insightful comments challenged the authors to amend their manuscripts and whose support was invaluable in making this special issue possible.

\section{References}

Alsamadani, R., Hallowell, M., \& Javernick-Will, A. N. (2013). Measuring and modelling safety communication in small work crews in the US using social network analysis. Construction Management and Economics, 31(6), 568-579.

Badi, S.; Wang, L. and Pryke, S. (2017a). Relationship Marketing in Guanxi networks: A Social Network Analysis Study of Chinese construction Small and Medium-sized Enterprises, Industrial Marketing Management, 60, 204-218

Badi, S. and Diamantidou, D (2017b). A Social Network Perspective of Building Information Modelling (BIM) in Greek Construction Projects. Architectural Engineering and Design Management, forthcoming.

Barnes, M. (1988) Construction project management, International Journal of Project Management, 6 (2), 69-79.

Baum, J.; Cowan, R. and Jonard, N. (2014) Does evidence of network effects on firm performance in pooled cross-section support prescriptions for network strategy? Strategic management Journal, 35 (5), 652-667.

Billinger, S. and Becker, M. (2014). Stability of organizational routines and the role of authority. DRUID Society Conference, 2014. 
Blomquist, T. and Lundin, R.A. (2010). Projects - real, virtual or what? International Journal of Managing Projects in Business, 3 (1), 10-21.

Blomquist, T., Hällgren, M., Nilsson, A. \& Söderholm, A. (2010) Project-as-practice. In search of project management research that matters, Project Management Journal, 41(1), 5-16.

Bresnen, M. (2006). Conflicting and conflated discourses? Project management, organisational change and learning in Hodgson, D. and Cicmil, S. (2006) Making projects critical, pp. 68-69.

Burger, M. and Sydow, J. (2014). How inter-organizational networks can become pathdependent: bargaining in the photonics industry. Schmalenbach Business Review 66.

Bygballe, L.E., Håkansson, H. and Jahre, M. (2013). A critical discussion of models for conceptualizing the economic logic of construction, Construction Management and Economics, 31(2) 104-118.

Chinowsky, P., Diekmann, J. and Galotti, V. (2008). Social network model of construction, Journal of Construction Engineering and Management, 134 (10), 804-812.

Chowdhury, A. N., Chen, P. H., \& Tiong, R. L. (2011). Analysing the structure of publicprivate partnership projects using network theory, Construction Management and Economics, 29(3), 247-260.

Davies, A. and Mackenzie, I. (2014). Project complexity and systems integration: Constructing the London 2012 Olympics and Paralympics Games. Project Management Journal, 32 (5), 773-790.

Di Marco, M. K., Taylor, J. E., and Alin, P. (2010). Emergence and role of cultural boundary spanners in global engineering project networks. Journal of Management in Engineering, 26 (3), 123-132. 
Dubois, A. and Gadde, L-E. (2000). Supply strategy and network effects - purchasing behaviour in the construction industry, European Journal of Purchasing \& Supply Chain Management, 6, 207-215.

Dubois, A and Gadde, L.E. (2002). The Construction Industry as a Loosely-Coupled System: Implications for Productivity and Innovation in Construction Management and Economics, 20 (7), 621-31.

Freeman, L. C. (1978). Centrality in social networks conceptual clarification. Social networks, 1(3), 215-239.

Geertz, C. (1973). The Interpretation of Cultures: Selected Essays, Basic Books, New York.

Grandori, A. and Soda, G. (1995) Inter-firm networks: antecedents, mechanisms and forms, Organisation Studies, 16(2), 183-214.

Granovetter, M. S. (1973). The strength of weak ties. American journal of sociology, 78(6), 1360-1380.

Håkansson, H., \& Ingemansson, M. (2013). Industrial renewal within the construction network. Construction Management and Economics, 31(1), 40-61.

Javernick-Will, A. (2011). Knowledge-sharing connections across geographical boundaries in global intra-firm networks. Engineering Project Organization Journal, 1 (4), 239-253. Higgin, G. and Jessop, N. (1965). Communications in the Building Industry: The Report of a Pilot Study. Tavistock Publications, London.

Hossain, L. (2009). Effect of organisational position and network centrality on project coordination, International Journal of Project Management, 27 (7), 680-689.

Hossain, L., and Wu, A. (2009). Communications network centrality correlates to organisational coordination, International Journal of Project Management, 27 (8), 795-811. 
Kang Sherman Heng, H., and Loosemore, M. (2013). Structural holes in hospital organisations: Facilities managers as entrepreneurial brokers in the tertiary health sector, Engineering, Construction and Architectural Management, 20 (5), 474-487.

Labianca, G. (2014). Negative ties in organizational networks. In Contemporary perspectives on organizational social networks (pp. 239-259). Emerald Group Publishing Limited.

Li, S., \& Ling, F. Y. (2012). Critical strategies for Chinese architectural, engineering and construction firms to achieve profitability, Engineering, Construction and Architectural Management, 19 (5), 495-511.

Li, Y., Lu, Y., Kwak, Y. H., Le, Y., \& He, Q. (2011). Social network analysis and organizational control in complex projects: construction of EXPO 2010 in China, Engineering Project Organization Journal, 1 (4), 223-237.

Lingard, H., Pirzadeh, P., Blismas, N., Wakefield, R., \& Kleiner, B. (2014). Exploring the link between early constructor involvement in project decision-making and the efficacy of health and safety risk control, Construction Management and Economics, 32 (9), 918-931.

Liu, L., Han, C., and Xu, W. (2015). Evolutionary analysis of the collaboration networks within National Quality Award Projects of China, International journal of project management, 33 (3), 599-609.

Loosemore, M. (1998). Social network analysis: using a quantitative tool within an interpretative context to explore the management of construction crises, Engineering, Construction and Architectural Management, 5 (4), 315-326.

Lundin, R.A. and Söderholm, A. (1995). A theory of the temporary organisation, Scandinavian Journal of Management, 11 (4), 437-455. 
Manning, S. and Sydow, J. (2007). Transforming creative potential in project networks: how TV movies are produced under network-based control, Critical Sociology, 33 (1-2), $19-42$.

Mead, S. P. (2001). Using social network analysis to visualize project teams, Project Management Journal, 32 (4), 32-38.

Morrison, J. (2014) The Social License: How to Keep Your Organization Legitimate, Palgrave Macmillan, London, UK.

Nohria, N. and Eccles, R.G. (eds) (1992). Networks and Organizations: Structure Form and Action. Harvard Business School Press, Boston.

Park, H., Han, S. H., Rojas, E. M., Son, J., and Jung, W. (2010). Social network analysis of collaborative ventures for overseas construction projects, Journal of construction engineering and management, 137 (5), 344-355.

Powell, W.W. (1990) Neither market nor hierarchy: network forms of organisation. Research in Organisational Behaviour.

Pryke, S.D. (2012). Social Network Analysis in Construction, Wiley-Blackwell, Oxford.

Pryke, S. D. (2017). Managing networks in project-based organisations Oxford: WileyBlackwell

Pryke, S.D., Badi, S. Soundararaj, B and Addyman, S.A. (2017). Self-Organising Networks in Complex Infrastructure Projects, In Project Management Journal [accepted August 2016]

Son, J., and Rojas, E. M. (2010). Evolution of collaboration in temporary project teams: An agent-based modeling and simulation approach, Journal of Construction Engineering and Management, 137 (8), 619-628.

Spender, J-C (1989), Industry Recipes: An Enquiry into the Nature and Sources of Managerial Judgement, Basil Blackwell, Oxford 
Syn, J. (2014) The social license: Empowering communities and a better way forward, Social Epistemology, 28 (3-4), 318-339.

Walker, F. and Pryke, S.D. (2008) The relationship between the degree of incompleteness and loss and expense claims in construction projects. Proceedings of the RICS Annual Construction, Building and Real Estate Research Conference (COBRA), Dublin, 4-5 September.

Wambeke, B. W., Liu, M., \& Hsiang, S. M. (2013). Task variation and the social network of construction trades, Journal of Management in Engineering, 30(4), 05014008.

Wasserman, S. and Faust, K. (1994). Social Network Analysis: Methods and Applications, Cambridge University Press, Cambridge.

Whyte, J. and Levitt, R. (2011). Information management and the management of projects. In P.W.G Morris, J.K. Pinto and J. Söderlund, The Oxford Handbook of Project Management, Oxford University Press, Oxford.

Winch, G. (1996). The contracting system in British construction: the rigidities of flexibility. Working Paper No.6 from Le Group Bagnolet c/o Bartlett School, UCL.

Winter, M., Smith, C., Morris, P. and Cicmil, S. (2006). Directions for future research in project management: the main findings of a UK government funded research network. International Journal of Project Management, 24 (8), 638-649.

Zhang, L., He, J., \& Zhou, S. (2012). Sharing tacit knowledge for integrated project team flexibility: Case study of integrated project delivery, Journal of Construction Engineering and Management, 139 (7), 795-804.

Zheng, X., Le, Y., Chan, A. P., Hu, Y., and Li, Y. (2016). Review of the application of social network analysis (SNA) in construction project management research, International Journal of Project Management, 34 (7), 1214-1225. 